\title{
Acquired Digital Fibrokeratoma: A Rare Case Study
}

\author{
Michael Judah McCann*, John Bonvillian and Cody Douglas Blazek \\ Wake Forest Baptist Hospital, PGY III, Dept of Orthopedic Surgery, 1 Medical Center Blvd Winston-Salem, NC 27157
}

*Corresponding author: Michael Judah McCann, Wake Forest Baptist Hospital, PGY III, Dept of Orthopedic Surgery; 1 Medical Center Blvd Winston-Salem, NC 27157

\begin{abstract}
Acquired digital fibrokeratomas are a benign soft tissue tumor with typical appearance and anatomical locations. This lesion generally occurs in middle aged males with common sites of occurrence in the digits of upper or lower extremities. Previous case studies have reported incidences of this lesion appearing on heels of middle-aged males but are generally described as giant digital fibrokeratoma based on the lesion's diameter. This case report describes an acquired digital fibrokeratoma in a pediatric female patient in an infrequent location.
\end{abstract}

Keywords: Acquired digital fibrokeratoma; Pediatric; Heel

\section{Introduction}

Acquired digital fibrokeratoma is a rare benign soft tissue tumor typically presenting on the hands and feet of middle-aged males. Clinical examination tends to reveal a solitary, round, firm, skin colored lesion less the 1 centimeter in diameter with either a sessile, dome-shaped or pedunculated base [1-4]. The patient's history could entail a slowing-growing lesion without any known traumatic event which becomes painful upon compression through enclosed shoes. Diagnosis of the lesion is accomplished through clinical and physical examination, various biopsy techniques and histological and surgical pathology evaluation. Treatment is dependent on the patient's desired outcomes. Conservative treatment entails offloading the lesion through various pads, proper shoe wear, or topical anesthetics. Surgical intervention entails removal of the lesion en-toto. Surgical intervention has been favored in recent times as the reoccurrence rate after excision has shown to be rare $[1,2,5]$. This case report describes an acquired digital fibrokeratoma in a pediatric female patient in an infrequent location.

\section{Case Report}

A 13-year-old female with past medical history significant for asthma, allergic rhinitis, atopic dermatitis, and eczema presented to clinic for a painful right heel lesion. The painful heel lesion began several months prior without any known traumatic events. Per the patient, the lesion began as a callus but progressed in size over the following months. Pain occurred with direct pressure secondary to enclosed shoe wear. Clinical examination revealed a firm, nonmobile, $7 \mathrm{~mm}$ circular skin lesion with a pedunculated based located on the posterior aspect of the heel. Previous treatments of offloading pads and topical callus remover were ineffective. Surgical intervention was warranted due to failed conservative treatments and an MRI with and without contrast was obtained to further evaluate the lesion. Obtained MRI showed a soft tissue mass involving the dermis and epidermis along the posterior heel without extension into underlying osseous, ligaments or tendon structures. An excisional biopsy was planned for removal of the skin mass. Under monitored anesthesia care a 3:1 elipse incision was made which encompassed the skin lesion in total. The incision was deepened into the subcutaneous layer and was excised in a full thickness flap. The proximal pole of the lesion was tagged with a 4-0 prolene suture and sent for pathological and histological examination. The wound was closed in usual manner, with sterile dressing application. She was allowed to weight bear in a CAM boot and seen in office on post-operative day 10. At post-operative visit one, she reported no pain, the surgical incision was well-coapted and sutures were removed. She was instructed to transition out of the CAM boot and into regular shoes over the following week and given a 4 week follow up appointment. She canceled her second post-operative appointment and was not seen in clinic again. Pathological report obtained confirmed a diagnosis of acquired digital fibrokeratoma. 


\section{Discussion}

In 1965, Steel published case reports on an unspecified periungual fibrous tumor which he described as a garlic-clove fibroma. Bart et al. reported on ten acral tumors in 1968 which were deemed similar to Steels previous findings but also resembled a "rudimentary supernumerary digit" with distinct histopathological findings and sites of occurrence. They termed the lesion as an acquired digital fibrokeratoma though suggested the lesion was not a fibroma rather a protrusion of the dermis [6,7]. Verallo et al also reported on 32 cases of similar lesions in 1968 as described by Bart et al. but with the expectation of six additional sites of occurrence. They suggested to omit the term "digital" from the name as described by Bart et al. to merit descriptive clarity. Reed et al. suggested the term acral to be utilized in describing the location of acquired fibrokeratomas. Recent case reports have described various locations of this lesion which lead authors to evolve the lesions descriptive terminology to acral fibrokeratoma [8-16]. Yi-Chiun Tsai et al. retrospectively reviewed 124 patients with a histopathological diagnosis of acquired digital fibrokeratoma over a 13-year period to characterize the distribution and surgical outcomes of these lesions. They found the mean age of occurrence to be 42 years, with a male predilection of $2: 1$, and 30/124 (24\%) of the lesions located on nondigital areas. Overall recurrence rate after surgical resection was 5/124 (4\%). Due to a low recurrence rate, surgical resection is generally recommended in treatment of these lesions. One most obtain a thorough history, clinical, physical, and histological evaluation for accurate diagnosis. Patients history general describes a slow growing lesion, without known trauma, which may become painful with compression. Physical examination reveals a small, firm, solitary, painless, skin tone color lesion which can arise in various locations. Under dermoscopy observation one visualizes a homogenous pale-yellow center surrounded by a hyperkeratotic scaly collarette with globular vessels located in the periphery of the lesion [16]. Histologically evaluation shows a benign fibroepithelial tumor, with acanthotic epidermis and thickened, often, branching rete ridges. The lesions core is formed by closely packed and interwoven collagen bundles which are generally vertically oriented. Elastic fibers are sparse but often the lesion is highly vascularized [1-4,17-19]. Differential diagnosis includes supernumerary digits in pediatric patients, cutaneous horns, pyogenic granuloma, exostosis keloid, dermatofibrosarcoma, eccrine poroma, neurofibroma and verruca $[1,5,18]$. The pathogenesis of acquired digital fibrokeratoma is unknown though mechanisms of occurrence have been proposed. Injury and minor trauma have been hypothesized as triggering factors, but case reports have not supported these mechanisms [1,18,20,21]. Kint et al. suggested neoformation of collagen produced acquired digital fibrokeratoma lesions based on histological findings of denser collagen fibers with capillaries and fibroblasts. They also described three types based on clinical and histological findings. Type I is noted to have a dome-shape and contains fibroblast between collagen bundles with fine elastic fibers and numerous capillaries in the dermis. Type II is a taller and hyperkeratotic lesion which contains more fibroblast and less elastic fibers then type I. Type
III can be flat or dome-shaped and is defined by poor cellular structures and no elastic fibers [18].

In this case, the patients age, sex, and lesion location were atypical. Previous published case studies have reported on acquired digital fibrokeratoma located on a patient 's heel but are generally observed in middle aged males and described as giant acquired digital fibrokeratomas [10,12,13,20,22]. Majority of acquired digital fibrokeratoma measure less than $1 \mathrm{~cm}$ in diameter. When lesions are greater than $1 \mathrm{~cm}$, they are described in the literature as a giant acquired digital fibrokeratomas [10,12,23,24]. To our knowledge, this is the first case report describing an acquired digital fibrokeratoma in a female pediatric patient located on the heel.

\section{References}

1. Boffeli TJ, Abben KW (2014) Acral fibrokeratoma of the foot treated with excision and trap door flap closure: a case report. J Foot Ankle Surg 53(4): 449-452.

2. Choi JH, Jung SY, Chun JS, Seo JK, Lee D, et al. (2001) Giant acquired digital fibrokeratoma occurring on the left great toe. Ann Dermatol 23(1): 64-66.

3. Baykal C, Buyukbabani N, Yazganoglu KD, Saglik E (2015) Acquired digital fibrokeratoma. Cutis 79(2): 129-132.

4. Beer TW (2009) Tumors of Fibrous Tissue Involving the Skin. In: Elder ED (Edt.), In Lever's Histopathology of the Skin, $\left(10^{\text {th }}\right.$ edn $)$, Lippincott Williams \& Wilkins, Philadelphia, USA, p. 989.

5. Yelamos O, Alegre M, Garcés JR, Puig L (2013) Periungual acral fibrokeratoma: surgical excision using a banner flap. Actas Dermosifiliogr 104 (9): 830-832.

6. Steel HH (1965) Garlic-clove fibroma. JAMA 191: 1082-1083.

7. Bart RS, Andrade R, Kopf AW, Leider M (1968) Acquired digital fibrokeratomas. Arch Dermatol 97(2): 120-129.

8. Verallo VV (1968) Acquired digital fibrokeratomas. Br J Dermatol 80(11): 730-736.

9. Reed NJ, Elmer LC (1971) Multiple acral fibrokeratomas (a variant of prurigo nodularis). Discussion of classification of acral fibrous nodules and of histogenesis of acral fibrokeratomas. Arch Dermatol 103(3): 287297.

10. De Freitas Pm, de Sb Xavier MH, Pereira GB, Rochael MC, de Oliveira Cortes JL, et al. (2008) Acquired fibrokeratoma presenting as a giant pedunculated lesion on the heel. Dermatol online J 14(12): 10.

11. Frydman AF, Mercer SE, Kleinerman R, Yanofsky VR, Birge MB (2010) Acquired fibrokeratoma presenting as multiple plantar nodules. Dermatol Online J 16(10): 5.

12. Bron C, Noël B, Panizzon RG (2004) Giant fibrokeratoma of the heel. Dermatology 208(3): 271-272.

13. Cooper PH, Mackel SE (1985) Acquired fibrokeratoma of the heel. Arch Dermatol 121(3): 386-388.

14. Altman DA, Griner JM, Faria DT (1994) Acquired digital fibrokeratoma. Cutis 54(2): 93-94.

15. Lee DR, Lee JY, Ahn JY, Park MY (2009) A case of acquired digital fibrokeratoma accompanied by pyogenic granuloma. Dermatol Online J 15(1): 8.

16. Rubegni P, Poggiali S, Lamberti A, Chiantini A, De Paola M, et al. (2012) Dermoscopy of acquired digital fibrokeratoma. Australas J Dermatol 53(1): 47-48. 
17. Tsai Yi Chiun, Hsiao PF, Wu YH (2017) Anatomical distribution and outcome of surgical excision of fibrokeratoma - a clinical analysis of 124 cases. Int J of Dermatolo 56(3): 337-340.

18. Kint A, Baran R, De Keyser H (1985) Acquired (digital) fibrokeratoma. J Am Acad Dermatol 12(5): 816-821.

19. Heenam PJ (2005) Tumors of fibrous tissue involving the skin: In: Elder ED (Edt), In Lever's Histopathology of the Skin, ( $9^{\text {th }}$ edn), Lippincott Williams \& Wilkins, Philadelphia, USA, p. 994.

20. Zakopoulou N, Bokotas C, Frangoulis M, Karypidis D, Hatziolou E, et al. (2009) Giant tumor of the heel: acquired fibrokeratoma. Clin Exp Dermtaol 34(5): 605-606.
21. Kakurai M, Yamada T, Kiyosawa T, Ohtsuki M, Nakagawa H (2003) Giant acquired digital fibrokeratoma. J Am Acad Dermatol 48(5): 67-68.

22. Cho EA, WS Lee, SY Kim (2007) A case of giant acquired digital fibrokeratoma resembling supernumerary digit. Kor J Dermatol 45(3): 319-320.

23. Spitalny AD, Lavery LA (1992) Acquired fibrokeratoma of the heel. J Foot Surg 31(5): 509-511.

24. Choi JH, Jung SY, Chun JS, Seo JK, Lee D (2011) Giant acquired digital fibrokeratoma occurring on the left great toe. Ann Dermatol 23(1): 6466.
(C) This work is licensed under Creative

To Submit Your Article Click Here:

Submit Article

DOI: $10.32474 / \operatorname{SCSOAJ} .2019 .03 .000162$

$\begin{gathered}\text { Surgery \& Case Studies: Open } \\ \text { Access Journal }\end{gathered}$
Assets of Publishing with us
GCSOAJ Global archiving of articles
- Immediate, unrestricted online access
- Rigorous Peer Review Process
- Authors Retain Copyrights

